\title{
ChemComm
}

\section{Matrix isolation and spectroscopic properties of the methylsulfinyl radical $\mathrm{CH}_{3}(\mathrm{O}) \mathrm{S}^{\bullet} \dagger$}

\author{
Cite this: Chem. Commun., 2013, \\ 49, 9467 \\ Received 16th July 2013, \\ Accepted 14th August 2013
}

DOI: $10.1039 / c 3 c c 45379 k$

www.rsc.org/chemcomm

The atmospherically highly relevant methylsulfinyl radical $\mathrm{CH}_{3}(\mathrm{O}) \mathrm{S}^{\bullet}$ was generated thermally under flash pyrolysis conditions and isolated in $\mathrm{Ar}$ matrices at $10 \mathrm{~K}$; the allyl radical is a byproduct. $\mathrm{CH}_{3}(\mathrm{O}) \mathrm{S}^{\bullet}$ and its $\mathrm{D}_{3}$ - and ${ }^{13} \mathrm{C}$-isotopologues were characterized through the excellent agreement between experimental and computed IR and UV/Vis spectra.

Elemental sulfur and its compounds are essential for the earth's biogeochemical system. Volatile organosulfur compounds are of key importance to the aerosol budget at the marine atmospheric boundary. ${ }^{1}$ Sulfate aerosol particles present above the oceans that evolve from planktonic algae-derived dimethyl sulfide (1) emissions affect the earth's radiation balance either by direct backscattering of solar radiation or indirectly via the cloud albedo by forming cloud condensation nuclei. ${ }^{1}$ The oxidation of 1 is believed to be initiated by reaction with $\mathrm{OH}$ or $\mathrm{NO}_{3}$ radicals and eventually leads to the formation of sulfuric and methanesulfonic acids (Scheme 1). While the methanethiyl (2), and methylsulfinyl radicals (3) were postulated as intermediates, 3 is insufficiently spectroscopically characterized. ${ }^{2}$

Sulfinyl radicals of type 3 have also been postulated to be products of scavenging of peroxide radicals by sulfenic acids causing the antioxidative effect of allium species widely used both in alternative and traditional medicine. ${ }^{3}$

Contrary to numerous theoretical reports, ${ }^{4}$ experimental spectroscopic studies for 3 have rarely been described. Whereas methods

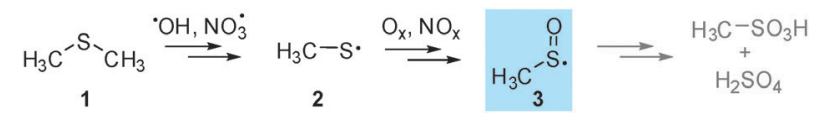

Scheme 1 Postulated reaction cascade for dimethyl sulfide oxidation to sulfuric acid and methylsulfonic acid in the atmosphere. ${ }^{2}$

\footnotetext{
${ }^{a}$ Institute of Organic Chemistry, Justus-Liebig University, Heinrich-Buff-Ring 58, D-35392 Giessen, Germany. E-mail: reisenauer@org.chemie.uni-giessen.de; Fax: +49-641-9934309; Tel: +49-641-9934380

${ }^{b}$ Department of Organic and Applied Chemistry, University of Lodz, Tamka 12, 91-493 Lodz, Poland. E-mail: gmloston@uni.lodz.pl; Fax: +4842 6655162; Tel: +48426355761

† Electronic supplementary information (ESI) available: Table, experimental, additional IR spectra and computational details. See DOI: 10.1039/c3cc45379k
}

such as ESR, ${ }^{5}$ mass spectrometry, ${ }^{6}$ and photoionization ${ }^{7}$ were successfully applied, there are no reports on the use of IR, UV/Vis or microwave spectra for the characterization of 3 . Only very recently a step scan FT-IR study on the oxidation of 2 with $\mathrm{O}_{2}$ tentatively assigned the most intense IR band. ${ }^{8}$ Methods for the generation of 3 comprise photochemical ${ }^{9}$ or multiphoton IR absorption, ${ }^{10}$ decomposition of DMSO, or the reaction of $\mathbf{1}$ with atomic oxygen. ${ }^{7,11}$ The focus of atmospheric chemistry studies was the determination of reaction rates for scavenging of 3 with $\mathrm{O}_{2}$, $\mathrm{O}_{3}$, and $\mathrm{NO}_{2} \cdot{ }^{12}$ However, many uncertainties concerning the reaction pathways and involved intermediates still exist. ${ }^{13}$

In connection with earlier experiments on the matrix isolation of sulfur containing intermediates ${ }^{14}$ we re-examined the vacuum flash pyrolysis of allylmethyl sulfoxide (4a) in combination with matrix isolation techniques. In contrast to reported results, ${ }^{15}$ only traces of the expected sulfine 5 and propene were detected in the matrix (Scheme 2, Fig. 1, also see Experimental in the ESI $\dagger$ ).

Since the thermal propene elimination from allyl sulfides is a standard method for the generation of thiocarbonyl compounds in the gas phase, ${ }^{16}$ the various reaction pathways in the pyrolysis of allylmethyl sulfide (6) and its S-oxide 4a deserve a comment. In both cases competitive processes (Scheme 2) are conceivable. On one hand, the concerted retro-ene reactions lead to propene

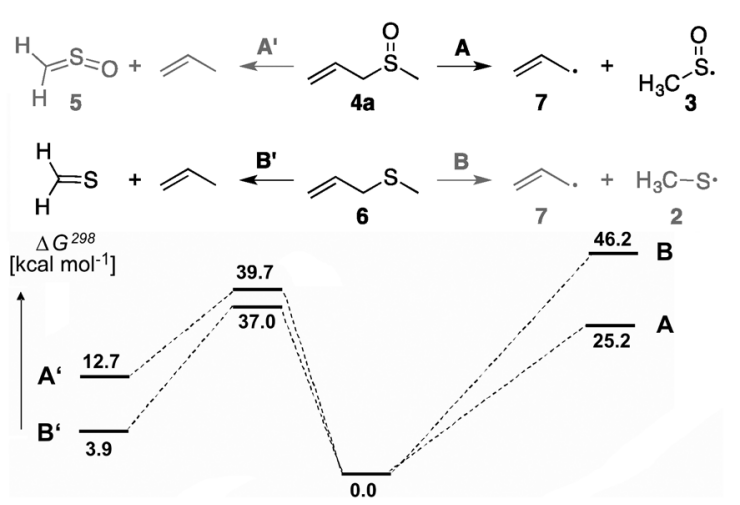

Scheme 2 Homolytic bond cleavage vs. concerted propene elimination from allylmethyl sulfoxide (4a) and allylmethyl sulfide (6); free energies at $298 \mathrm{~K}^{\text {in kcal mol}} \mathrm{m}^{-1}$ computed at the $\mathrm{G} 4$ level of theory. 


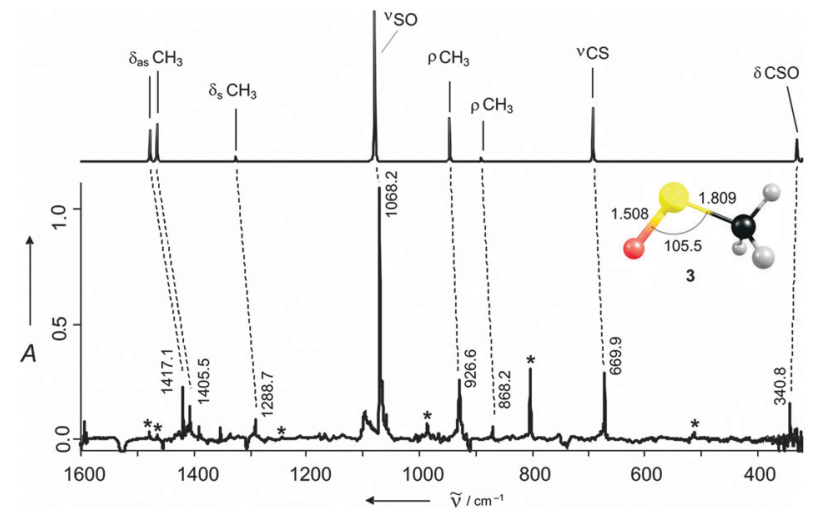

Fig. 1 IR spectrum and structure (bond lengths in $\AA$, angles in deg.) of 3. Top: computed at AE-CCSD(T)/cc-pVTZ (harmonic approx., no scaling); bottom: experimental (Ar matrix, $10 \mathrm{~K}$ ) difference spectrum, obtained by subtracting the spectrum of the photolyzed matrix $(254 \mathrm{~nm}, 15 \mathrm{~h}$ ) from the non-irradiated pyrolysis products of precursor $4 \mathrm{a}\left(2 \mathrm{~h}\right.$ at $\left.660^{\circ} \mathrm{C}\right)$, bands of 7 are marked with *

and thioformaldehyde (for 6) or to thioformaldehyde S-oxide (5) (for 4a). On the other hand, homolytic cleavage of the $\mathrm{C}-\mathrm{S}$ bonds in $\mathbf{4 a}$ and 6 yield the allyl radical (7) formed next to 3 or 2 , respectively. The different behaviour of $\mathbf{4 a}$ and 6 under pyrolytic conditions can be explained by comparison of the $\Delta G^{\ddagger}$ values for the concerted retro-ene reactions with the BDEs computed at the Gaussian-4 (G4) level of theory. While the $\Delta G^{\ddagger}$ values of the retro-ene reactions are in both cases nearly equal, the energy for radical pair formation is more than $20 \mathrm{kcal} \mathrm{mol}^{-1}$ lower for $\mathbf{4 a}$. Hence, only the radical pair forms in this case; this is also supported by the differences in BDEs for the breaking bonds. ${ }^{16 b}$

Indeed, very intense IR absorption bands corresponding to $7^{17}$ and 3 are evident ( $c f$. Fig. S1 in ESI $\dagger$ ). The unambiguous assignment of the latter follows directly from the comparison of the experimental data with the $a b$ initio computed (AE-CCSD(T)/cc-pVTZ) IR spectrum (Fig. 1, Table S1 in ESI $\dagger$ ). The most intense band (SO stretching vibration) appears at $1068.2 \mathrm{~cm}^{-1}$. This value is in good agreement with the reported gas phase value derived from the FT-IR step scan experiment $1071 \mathrm{~cm}^{-1.8}$. The less intense absorption band of the CS stretching vibration was found at $669.9 \mathrm{~cm}^{-1}$ along with the another band at $340.8 \mathrm{~cm}^{-1}$ for the CSO bending mode. Moreover, seven additional bands were attributed to $\mathrm{CH}$ stretching and bending vibrations. Only one out of the total number of twelve fundamental bands, namely the twisting vibration of the methyl group, was not observed in the experiment because its expected position $\left(134 \mathrm{~cm}^{-1}\right)$ was located below the range of the spectrometer used.

The geometry of 3 ( $c f$. Fig. 1) bears no surprises. The location of the unpaired electron spin density, however, is less clear. The ${ }^{2} \mathrm{~A}^{\prime \prime}$ state ( $\pi$-radical) is more favourable than the ${ }^{2} \mathrm{~A}^{\prime}$ state ( $\sigma$-radical) by more than $40 \mathrm{kcal} \mathrm{mol}^{-1}$ at the UHF and UB3LYP levels of theory utilizing a large $6-311+\mathrm{G}(3 \mathrm{df}, 3 \mathrm{pd})$ basis set ( $c f$. Fig. S5, ESI $\dagger$ ). The spin distribution for the ${ }^{2} \mathrm{~A}^{\prime \prime}$ state is approximately even on the sulfur and oxygen atoms. ${ }^{2 d}$

To support the proposed assignments, the spectra of the $\mathrm{D}_{3}$-and ${ }^{13} \mathrm{C}$-isotopologues $\mathbf{4 b}$ and $\mathbf{4} \mathbf{c}$ were recorded under the same experimental conditions. The intermediate allylmethyl sulfides $\mathbf{6 b}$ and $\mathbf{6 c}$ were prepared by treatment of sodium allylthiolate with $\mathrm{CD}_{3} \mathrm{I}$ or ${ }^{13} \mathrm{CH}_{3} \mathrm{I}$, respectively, and were subsequently oxidized in methanolic solution using $\mathrm{H}_{2} \mathrm{O}_{2}$ (Scheme 3, see also ESI $\dagger$ ). ${ }^{18}$

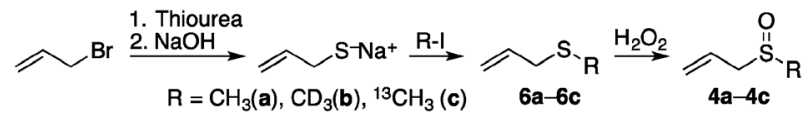

Scheme 3 Synthesis of $\mathbf{4 a}$ and its labelled derivatives $\mathbf{4 b}$ and $\mathbf{4 c}$.

The observed isotopic band shifts of the two isotopologues $\mathbf{4 b}$ and $\mathbf{4 c}$ are in excellent agreement with the computed values. For example, the CS band is shifted by $-13.9 \mathrm{~cm}^{-1}$, compared to the computed value of $-14.1 \mathrm{~cm}^{-1}$, whereas the SO stretching showed practically no shift (exp. -0.3 , computed $0.0 \mathrm{~cm}^{-1}$ ) upon ${ }^{13} \mathrm{C}$-labelling. Similarly, the experimental and computed IR band shifts of the $\mathrm{D}_{3}$-isotopologue 4b are in good agreement. Thus, in the case of the CS stretching vibration, which mixes with one of the $\mathrm{CH}$ bending modes, the experimental data show a shift of $-55.7 \mathrm{~cm}^{-1}$ (calcd $-60.2 \mathrm{~cm}^{-1}$ ). In accordance with the computations, the shift of the SO stretching vibration displays a small positive value (exp. +1.5 , calcd $\left.+4.7 \mathrm{~cm}^{-1}\right)$.

The matrix isolated products of pyrolysis were also characterized using UV/Vis spectroscopy (Fig. 2). As expected, the recorded spectra showed a weak absorption band of 7 with its characteristic vibrational fine structure between $409 \mathrm{~nm}$ and about $320 \mathrm{~nm}$, which is well known from literature data. ${ }^{17 a}$ From the second, much stronger band of $7,\left(\lambda_{\max }=213 \mathrm{~nm}\right)$ only a part of the absorption could be observed. Structure 3 shows two absorption bands that differ strongly in intensities. One is very weak displaying a pronounced vibrational fine structure starting at $635 \mathrm{~nm}$ and terminating at around $450 \mathrm{~nm}\left(\lambda_{\max } \cong 530 \mathrm{~nm}\right)$. The second much more intense one starts near $320 \mathrm{~nm}\left(\lambda_{\max }\right.$ at ca. $260 \mathrm{~nm}$ ) and overlaps with the very strong band of 7. Both bands of 3 correlate well with the values of the electronic excitations computed using time-dependent density functional theory (TD-DFT) computations at TD-UB3LYP/6-311+G(3df,3pd) (Table 1).

Our computations place the lowest energy transition from the electronic ground state to the first excited electronic state $\left((\mathrm{A})^{2} \mathrm{~A}^{\prime \prime} \leftarrow(\mathrm{X})^{2} \mathrm{~A}^{\prime \prime}\right)$ at $540 \mathrm{~nm}$ with an extremely low oscillator strength of 0.0005 . The second transition $\left(\mathrm{B}\left({ }^{2} \mathrm{~A}^{\prime \prime}\right) \leftarrow \mathrm{X}\left({ }^{2} \mathrm{~A}^{\prime \prime}\right)\right)$, theoretically at $255 \mathrm{~nm}$ with an even lower intensity, is hidden under the very close-lying third absorption band $\left(\mathrm{C}\left({ }^{2} \mathrm{~A}^{\prime}\right) \leftarrow \mathrm{X}\left({ }^{2} \mathrm{~A}^{\prime \prime}\right)\right)$ $(250 \mathrm{~nm})$ that is also two orders of magnitudes more intense. According to the orbitals involved in the corresponding electronic excitations (see ESI $\dagger$ ), the weak absorption band in the visible range is an $n \rightarrow \pi^{*}$ transition and the short wavelength intense band a $\pi \rightarrow \pi^{*}$ transition.

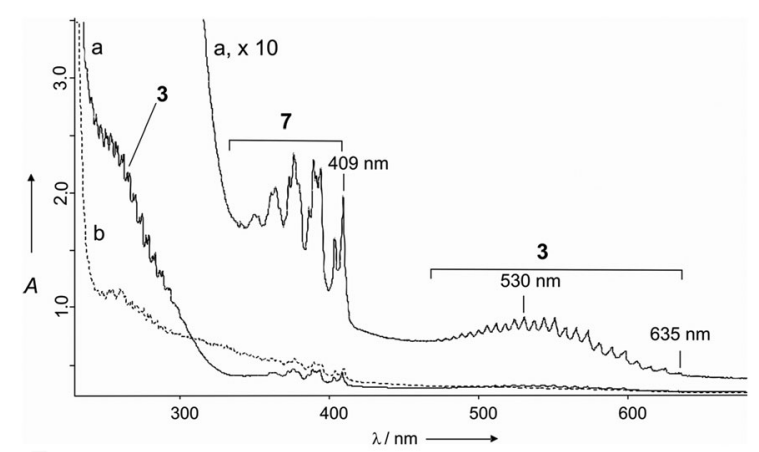

Fig. 2 The UV/Vis absorption spectrum of the matrix isolated (Ar, $10 \mathrm{~K}$ ) pyrolysis products of precursor $4 \mathrm{a}\left(2 \mathrm{~h}\right.$ pyrolysis at $\left.660{ }^{\circ} \mathrm{C}\right)$; upper trace $(\times 10)$; (b) after $50 \mathrm{~min}$ irradiation with $248 \mathrm{~nm}$ light ( $\mathrm{KrF}$ excimer laser). 
Table 1 Computed electronic transitions of 3 from the electronic ground state to the first three lowest excited states (TD-UB3LYP/6-311+G(3df,3pd)) and experimental UV/Vis bands of $\mathbf{3}(\mathrm{Ar}, 10 \mathrm{~K})$

\begin{tabular}{llllll}
\hline State & $E(\mathrm{eV})$ & $\lambda_{\max }(\mathrm{nm})$ & Osc. str. & Trans. & Exptl. $\lambda_{\max }(\mathrm{nm})$ \\
\hline $\mathrm{A},{ }^{2} \mathrm{~A}^{\prime \prime}$ & 2.295 & 540 & 0.0005 & $\mathrm{n} \rightarrow \pi^{*}$ & ca. 530 \\
$\mathrm{~B},{ }^{2} \mathrm{~A}^{\prime \prime}$ & 4.853 & 255 & 0.0001 & $\pi \rightarrow \pi^{*}$ & n.o. \\
$\mathrm{C},{ }^{2} \mathrm{~A}^{\prime}$ & 4.954 & 250 & 0.0343 & $\pi \rightarrow \pi^{*}$ & ca. 260
\end{tabular}

The knowledge about the position of the absorption bands of $\mathbf{3}$ allows irradiation at specific wavelengths. While excitation with visible light did not induce photochemical transformations even after long irradiation times, photolysis of the matrix with selected wavelengths corresponding to the more intense UV-band of 3 (248 nm, $254 \mathrm{~nm}$, and $290 \mathrm{~nm}$ ) led to the simultaneous disappearance of both the IR as well as UV/Vis bands of 3. After photolysis a mixture of products such as $\mathrm{CO}, \mathrm{COS}, \mathrm{H}_{2} \mathrm{O}$, CS, and thioformic acid was identified based on the IR absorption bands. Despite this rather unspecific decomposition, the differences between the spectra taken before and after irradiation allowed enhancement of the spectral features of 3, as shown in Fig. 1. Note that upon photolysis the photocylization of 7 leading to the cyclopropyl radical was largely suppressed. ${ }^{17 d}$

In an extension of this study, we also tested dimethyl sulfoxide (8) as an alternative precursor for thermally generated 3 in the reaction $\mathrm{H}_{3} \mathrm{C}(\mathrm{SO}) \mathrm{CH}_{3} \rightarrow 3+{ }^{\circ} \mathrm{CH}_{3}$. In accordance with the expected increase of the CS bond dissociation energy as compared to precursor $4 a$ (computed at B3LYP/6-311+G(3df,3pd): $21 \mathrm{kcal} \mathrm{mol}^{-1}$ ), this pyrolysis had to be performed at a significantly higher temperature $\left(800{ }^{\circ} \mathrm{C}\right)$.

The pyrolysate collected in the Ar matrix was analysed by means of IR spectroscopy. In this case, however, the characteristic bands of 3 and those of the methyl radical were observed along with the unconverted starting material, forming a major component of the collected pyrolysate. In addition, small amounts of $\mathbf{5}$, and methane were also observed. Hence, $\mathbf{8}$ is a poor precursor of $\mathbf{3}$.

In summary, radical 3 as well as its $\mathrm{D}_{3}$ - and ${ }^{13} \mathrm{C}$-isotopologues were generated by high-vacuum flash pyrolysis and isolated in solid argon at $10 \mathrm{~K}$ starting either with allylmethyl sulfoxide (4a) or its isotopologues $\mathbf{4 b}$ and $\mathbf{4 c}$, respectively, or with dimethyl sulfoxide (8). The identity of $\mathbf{3}$ was unambiguously confirmed based on the good agreement of measured and computed IR spectra at the AE-CCSD(T)/ cc-pVTZ level of theory. The recorded UV/Vis spectrum showing a very weak band in the visible range (635-450 nm) due to an $\mathrm{n} \rightarrow \pi^{*}$ transition and a more intense $\pi \rightarrow \pi^{*}$ absorption $\left(\lambda_{\max } \cong 260 \mathrm{~nm}\right)$ corresponds well with TD-DFT computations. As evident from the IR spectra, photolysis of 3 using UV light $(\lambda<300 \mathrm{~nm})$ leads to an unspecific decomposition. The presented new method for the efficient generation of 3 opens the door to further studies on the structures of products formed in its reactions with atmospheric gases such as $\mathrm{O}_{2}, \mathrm{O}_{2}$ or $\mathrm{NO}_{2}$. These reactions have been postulated to be the main degradation pathways for 3 in the atmosphere and they deserve further in-depth investigation.

We dedicate this work to our dear colleague Bogusław Kryczka on the occasion of his 70th birthday. This work was supported by the DAAD Partnership of the University of Lodz and the JustusLiebig University. G. M. thanks the National Science Center (Poland) for financial support (Project Maestro-3; Dec-2012/06/A/ST5/00219).

\section{Notes and references}

1 (a) R. J. Charlson, J. E. Lovelock, M. O. Andreae and S. G. Warren, Nature, 1987, 326, 655; (b) B. Albrecht, Science, 1989, 245, 1227; (c) R. J. Charlson, S. E. Schwarz, J. M. Hales, R. D. Cess, J. A. Coakley, Jr., J. E. Hansen and D. J. Hofmann, Science, 1992, 425, 423; (d) M. O. Andreae, C. D. Jones and P. M. Cox, Nature, 2005, 435, 1187; (e) I. Faloona, Atmos. Environ., 2009, 43, 2841.

2 (a) G. S. Tyndall and A. R. Ravishankara, Int. J. Chem. Kinet., 1991, 23, 483; (b) S. B. Barone, A. A. Turnipseed and A. R. Ravishankara, Faraday Discuss., 1995, 100, 39; (c) I. Barnes, J. Hjorth and N. Mihalopoulos, Chem. Rev., 2006, 106, 940; (d) D. D. Gregory and W. S. Jencks, J. Org. Chem., 1998, 63, 3859.

3 (a) E. Block, Angew. Chem., Int. Ed., 1992, 31, 1135; (b) V. Vaidya, K. U. Ingold and D. A. Pratt, Angew. Chem., Int. Ed., 2009, 48, 157.

4 (a) S. M. Resende and F. R. Ornellas, Chem. Phys. Lett., 2003, 367, 489; (b) X. Li, L. Meng and S. Zheng, THEOCHEM, 2007, 847, 52; (c) X.-Y. Li, L.-P. Meng and S.J. Zheng, Chin. J. Chem., 2007, 25, 1480; (d) R. Asatryan and J. W. Bozzelli, Phys. Chem. Chem. Phys., 2008, 10, 1769; (e) X. Li, L. Meng, Z. Sun and S. Zheng, THEOCHEM, 2008, 870, 53; $(f)$ A. Lesar, Int. J. Quantum Chem., 2012, 112, 1904; $(g)$ Z. Salta, A. M. Kosmas and A. Lesar, Comput. Theor. Chem., 2012, 1001, 67.

5 (a) G. K. Buerk and G. Schoffa, Int. J. Protein Res., 1969, 1, 113; (b) T. Kawamura, P. J. Krusic and J. K. Kochi, Tetrahedron Lett., 1972, 4075; (c) J. C. Machado, R. Debuyst, F. Dejehet and D. Apers, Radiochem. Radioanal. Lett., 1972, 9, 363; (d) K. Nishikida and F. Williams, J. Am. Chem. Soc., 1974, 96, 4781; (e) B. C. Gilbert, C. M. Kirk, R. O. C. Norman and H. A. H. Laue, J. Chem. Soc., Perkin Trans. 2, 1977, 497; $(f)$ D. J. Nelson, J. Phys. Chem., 1978, 82, 1400; $(g)$ S. G. Swarts, D. Becker, S. DeBolt and M. D. Sevilla, J. Phys. Chem., 1989, 93, 155.

6 F. Turecek, D. E. Drinkwater and F. W. McLafferty, J. Am. Chem. Soc., 1989, 111, 7696.

7 W.-C. Hung, M.-Y. Shen, Y.-P. Lee, N.-S. Wang and B.-M. Cheng, J. Chem. Phys., 1996, 105, 7402; B.-M. Cheng, E. P. Chew, W.-C. Hung, J. Eberhard and Y.-P. Lee, J. Synchrotron Radiat., 1998, 5, 1041.

8 L.-K. Chu and Y.-P. Lee, J. Chem. Phys., 2010, 133, 184303.

9 (a) D. A. Blank, S. W. North, D. Stranges, A. G. Suits and Y. P. Lee, J. Chem. Phys., 1997, 106, 539; (b) G. M. Thorson, C. M. Cheatum, M. J. Coffey and F. Fleming Crim, J. Chem. Phys., 1999, 110, 10843; (c) J.-W. Ho, W.-K. Chen and P. Y. Cheng, J. Am. Chem. Soc., 2007, 129, 3784.

10 (a) H. Gross, Y. He, M. Quack, A. Schmid and G. Seyfang, Chem. Phys. Lett., 1993, 213, 121; (b) H. Gross, Y. He, M. Quack and G. Seyfang, Springer Proc. Phys., 1994, 74, 169.

11 D. L. Singleton, R. S. Irwin and R. J. Cvetanovic, Can. J. Chem., 1983, 61, 968.

12 (a) F. Domine, T. P. Murrells and C. J. Howard, J. Phys. Chem., 1990, 94, 5839; (b) G. S. Tyndall and A. R. Ravishankara, J. Phys. Chem., 1989, 93, 2426; (c) F. Domine, A. R. Ravishankara and C. J. Howard, J. Phys. Chem., 1992, 96, 2171; (d) A. Kukui, V. Bossoutrot, G. Laverdet and G. Le Bras, J. Phys. Chem. A, 2000, 104, 935; (e) D. Borissenko, A. Kukui, G. Laverdet and G. Le Bras, J. Phys. Chem., 2003, 107, 1155.

13 D. D. Lucas and R. G. Prinn, Atmos. Chem. Phys., 2005, 5, 1505.

14 (a) J. Romanski, H. P. Reisenauer, H. Petzold, W. Weigand, P. R. Schreiner and G. Mloston, Eur. J. Org. Chem., 2008, 2998; (b) G. Mloston, J. Romanski, H. P. Reisenauer and G. Maier, Angew. Chem., Int. Ed., 2001, 113, 401; (c) H. P. Reisenauer, G. Mloston, J. Romanski and P. R. Schreiner, Eur. J. Org. Chem., 2011, 6269; (d) H. P. Reisenauer, G. Mloston, J. Romanski and P. R. Schreiner, J. Am. Chem. Soc., 2010, 132, 7240; (e) H. P. Reisenauer, G. Mloston, J. Romanski and P. R. Schreiner, Eur. J. Org. Chem., 2012, 3480. For review, see: $(f)$ G. Mloston, J. Romanski, H. P. Reisenauer and P. R. Schreiner, Phosphorous, Sulfur, Silicon, 2011, 186, 1175.

15 D. E. Powers, C. A. Arrington, W. C. Harris, E. Block and V. F. Kalasinsky, J. Phys. Chem., 1979, 83, 1890.

16 (a) H. Bock, T. Hirabayashi and S. Mohmand, Chem. Ber., 1982, 115, 492; (b) A. J. McGrath, G. E. Garrett, L. Valgimigli and D. A. Pratt, J. Am. Chem. Soc., 2010, 132, 16759.

17 (a) G. Maier, H. P. Reisenauer, B. Rohde and K. Dehnicke, Chem. Ber., 1983, 116, 7323; (b) A. K. Mal'tsev, V. A. Korolov and O. M. Nefedov, Bull. Acad. Sci. USSR Div. Chem. Sci., 1982, 2131; (c) A. K. Mal'tsev, V. A. Korolov and O. M. Nefedov, Bull. Acad. Sci. USSR Div. Chem. Sci., 1984, 510; (d) K. Holtzhauer, C. ComettaMorini and J. F. M. Oth, J. Phys. Org. Chem., 1990, 219.

18 B. Prabhuswamy and S. Y. Ambekar, Synth. Commun., 1999, 29, 3477; M. L. Kline, N. Beutow, J. K. Kim and M. C. Caserio, J. Org. Chem., 1979, 44, 1904; D. E. O'Connor and W. I. Lyness, J. Am. Chem. Soc., 1964, 86, 3840. 